López De Lara, D. (2014). Cuatro factores internacionales para el cambio democrático en México (1990-2006). Collectivus, Revista de Ciencias Sociales, 1, (1), 46-69. Julio - Diciembre. ISSN: 2382-4018

Recibido: 30/09/2013

Aceptado versión definitiva: 04/12/2013

\title{
CUATRO FACTORES INTERNACIONALES PARA EL CAMBIO DEMOCRÁTICO EN MÉXICO (1990-2006)
}

\author{
DAINZÚ LÓPEZ DE LARA E ${ }^{1}$ \\ Instituto de Estudios Internacionales. Universidad del mar - Campus Huatulco, \\ Ciudad Universitaria, Santa María Huatulco, Oax., México, c.p. 70989. \\ dainzu.umar@gmail.com
}

\section{RESUMEN}

Durante la mayor parte del siglo XX, México se mantuvo aislado de la influencia externa a causa del sesgo estatista y nacionalista de su política exterior. Debido a un sistema político autoritario presidencialista, de partido hegemónico y pluralismo limitado. Durante los años 1990 se fueron implementando reformas económicas y políticas, influenciadas por cuatro actores externos: Estados Unidos, ONU, OEA y Unión Europea. Aquí se revisan momentos históricos clave que incidieron para la apertura democrática en México. La influencia se centró en dos áreas principales: 1) Derechos humanos, donde se aceptó la observación internacional y 2) en los procesos electorales, que generaron reformas que dieron paso al proceso de transición a la democracia en México.

Palabras clave: Política exterior, México, factor internacional, organismos internacionales.

\footnotetext{
${ }^{1}$ Doctora en Ciencias Políticas - Relaciones Internacionales por el Instituto de Altos Estudios de América Latina (IHEAL), Sorbonne Nouvelle, París III. Profesora-investigadora de tiempo completo en el Instituto de Estudios Internacionales (IEI) de la Universidad del Mar (UMAR) campus Huatulco.
} 
López De Lara, D. (2014). Cuatro factores internacionales para el cambio democrático en México (1990-2006). Collectivus, Revista de Ciencias Sociales, 1, (1), 46-69. Julio - Diciembre. ISSN: 2382-4018

FOUR INTERNATIONAL FACTORS FOR DEMOCRATIC CHANGE IN MEXICO (1990-2006).

\section{ABSTRACT}

For the most part of the twentieth century, Mexico remained isolated from outside influence because of its nationalist and statist bias of its foreign policy, this because of a presidential authoritarian political system, of hegemonic party, and limited pluralism. During the 1990s were implemented economic and political reforms, influenced by four external actors: United States, United Nations, OAS, and European Union. Here, key historical moments that induced the democratic opening in Mexico are reviewed. Their influence focused on two main areas: 1) human rights, where international observation was accepted, and 2) electoral processes, which generate reforms that led to the transition to democracy in Mexico.

Key words: foreign policy, Mexico, international factors, international organizations.

\section{Introducción}

La intensificación de las relaciones internacionales, llamada globalización conlleva a un aumento en la interacción de los factores internos y externos que permite entender cómo la política internacional y las estructuras domésticas se afectan mutuamente (Gourevitch, 1978, pp. 881-882). Tradicionalmente, el sistema internacional se ha visto como una variable explicativa de la estructura interna de los Estados, aunque éste a su vez es una consecuencia de las políticas nacionales. En otras palabras, las relaciones internacionales y la política doméstica están tan interrelacionadas que deben ser analizadas simultáneamente. Aquí observamos la forma en la que el ambiente internacional influye en la estructura política interna; la forma en la que México se ha adaptado al sistema internacional y los cambios que han surgido de ello. Esta dinámica inicia formalmente en la década de los noventa, 
López De Lara, D. (2014). Cuatro factores internacionales para el cambio democrático en México (1990-2006). Collectivus, Revista de Ciencias Sociales, 1, (1), 46-69. Julio - Diciembre. ISSN: 2382-4018

en estrecha relación con los cambios en la economía y geopolítica internacional, que imponen nuevas reglas del juego.

Para ello identificamos cuatro factores internacionales o externos (Estados Unidos, la ONU, la OEA y la Unión Europea) que han inducido o influido el cambio democrático en México. La hipótesis de este trabajo sostiene que estos actores internacionales han participado e influido en la transición democrática mexicana, particularmente desde los años noventa, en dos aspectos centrales: el electoral y el de derechos humanos. Algunos de estos cambios son inducidos por los procesos de integración regional o acuerdos comerciales. La aceptación de recomendaciones, observaciones y cláusulas democráticas llevan a los gobiernos mexicanos a introducir reformas, primero económicas y más tarde de liberalización política. En estas segundas el gobierno de Vicente Fox (2000-2006) ostenta un papel preponderante en la aprobación de mecanismos de vigilancia y asesoría técnica para la protección de los derechos humanos. Si bien los gobiernos de Carlos Salinas (1988-1994) y Ernesto Zedillo (1994-2000) inician la liberalización económica y política, es el gobierno de Fox quien emprende pasos significativos para asumir compromisos internacionales con la normatividad internacional en materia de derechos humanos. ${ }^{2}$ Esto constituye un claro rompimiento con la "tradicional renuencia de los gobiernos del PRI al monitoreo externo" (Pellicer, O. \& González Iza, G. 2008, p. 167).

Con el fin de la guerra fría, la defensa de los derechos humanos y la democracia se vuelven temas prioritarios en la agenda internacional. Se realinean las estructuras de poder, caracterizadas por la división bipolar. Cobran legitimidad y proyección internacional concepciones de la democracia liberal, apertura comercial y promoción de los derechos humanos. Ello

\footnotetext{
${ }^{2}$ Los compromisos internacionales asumidos por el gobierno de Fox en cuanto a la aplicación interna del derecho internacional queda en evidencia con la importante firma del Acuerdo de Cooperación Técnica con la Alta Comisionada de Derechos Humanos de la ONU, el cual marca el inicio de una intensa cooperación con la ONU, editándose un documento con el diagnóstico de temas pendientes y recomendaciones. El compromiso de este gobierno con los derechos humanos lleva a que cada dependencia de gobierno vele por ellos desde su trinchera, es decir la transversalidad [sic.] de los derechos humanos en todas las áreas de la vida pública mexicana. Además se acepta el Estatuto de Roma de la Corte Penal Internacional (CPI) como el segundo gran compromiso de este gobierno para apoyar la acción multilateral con un "órgano judicial
} 
López De Lara, D. (2014). Cuatro factores internacionales para el cambio democrático en México (1990-2006). Collectivus, Revista de Ciencias Sociales, 1, (1), 46-69. Julio - Diciembre. ISSN: 2382-4018

significaba un claro rompimiento con el pasado comunista (Salas, F. 2002, p. 163). Este autor describe como las repúblicas bálticas y otros Estados surgidos de la desintegración de la URSS, se convierten en "creativos arquitectos de estructuras democráticas", usando como modelo esquemas occidentales. Esto se debe a que el mejor resguardo para sus nacientes democracias consistía, precisamente, en acompañarse en el ámbito internacional de otras democracias. Esto se traduce en "cooperación internacional", donde se reconoce que los gobiernos no pueden alcanzar solos sus objetivos internos, tales como la lucha contra el calentamiento global, la liberalización de la economía internacional, la integración de los sistemas de comunicación, el combate al terrorismo y el crimen organizado, así como la regulación de corporativos multinacionales.

Los organismos internacionales adquieren entonces una nueva vigencia, ante un sistema internacional "multipolar". La defensa del multilateralismo se da en ámbitos como la paz, la seguridad internacional, así como la defensa de los derechos humanos y la democracia. La promoción de los derechos humanos constituyó un legítimo reclamo después de medio siglo de represión en aquellas nacientes democracias de Europa del Este. Si bien dentro de los regímenes democráticos existen también violaciones a los derechos humanos, un sistema democrático se fundamenta en la existencia de estos derechos y la mejor forma de luchar por ellos es mediante la consolidación de estructuras democráticas (ob. Cit, p. 164). Esto se traduce en una mayor apertura de los procesos políticos internos al escrutinio internacional; la actualización en la vinculación de instrumentos internacionales en materia de derechos humanos y en algunos casos, en la creación de nuevas estructuras, como la Corte Penal Internacional (CPI). Se buscó que los organismos internacionales tanto de vocación universal como regional, impulsaran nuevos esquemas jurídicopolíticos, como también la negociación de acuerdos comerciales o de integración regional. Como lo señalan Mansfield, E. y Pevehouse, J.C. (2006, p. 138): "Los países que están bajo un proceso de transición a la democracia son propensos a incorporarse a organizaciones internacionales, ante la falta de 
López De Lara, D. (2014). Cuatro factores internacionales para el cambio democrático en México (1990-2006). Collectivus, Revista de Ciencias Sociales, 1, (1), 46-69. Julio - Diciembre. ISSN: 2382-4018

credibilidad que pueden tener sus líderes, al momento de sostener reformas liberales y consolidar su democracia".

Las instituciones multilaterales incluyen a los organismos internacionales, y la participación en ellas, a menudo ayuda a las instituciones democráticas internas a restringir el poder de grupos que persiguen un interés "especial". Para con ello proteger los derechos individuales y mejorar la calidad de la deliberación democrática colectiva (Keohane, R.O., Macedo, S. \& Moravcsik, A. 2009, p. 2).

En América Latina, la transición a la democracia también surte un efecto transformador, las nacientes democracias latinoamericanas se unen a los avances de los derechos humanos, los cuales, en muchos casos, obedecieron a causas endógenas que anteceden la caída del muro de Berlín (Salas, F. 2002, p. 165). Los procesos de pacificación en América Central se construyen a partir de esfuerzos multilaterales, como Contadora (1983), Esquipulas I (1986) y Esquipulas II (1987). En los cuales se buscaba erradicar las constantes violaciones a los derechos humanos e implementar, eventualmente, regímenes democráticos.

Para México, las nuevas circunstancias de economía abierta, democratización y un mundo fuertemente dominado por una potencia hegemónica, lo obligan a revisar las grandes directrices de la política exterior. Durante décadas, México implementa una política exterior "nacionalista", con un claro sesgo "estatista" y "centralista", que viene de su experiencia histórica y de su vecindad con Estados Unidos. Esto corresponde a un:

Sistema político autoritario, presidencialista, de partido dominante y pluralismo limitado. Así como a una economía mixta y cerrada; que sirve para atender demandas proteccionistas del modelo de industrialización de sustitución de importaciones y aislar, la vida política interna de influencias o intervenciones del exterior. (González, G. 2006, p. 156).

Durante los ochenta y noventa se inician una serie de reformas económico-estructurales que reorientan la diplomacia mexicana con una 
López De Lara, D. (2014). Cuatro factores internacionales para el cambio democrático en México (1990-2006). Collectivus, Revista de Ciencias Sociales, 1, (1), 46-69. Julio - Diciembre. ISSN: 2382-4018

marcada inclinación económica. Además de una atención importante a los países desarrollados, un mayor pragmatismo y una mayor colaboración con Estados Unidos. Todo ello se traduce en el comportamiento internacional de México, que oscila entre dos visiones heredadas, la del nacionalismo revolucionario y la del pragmatismo económico, con una tercera visión multilateralista y liberal centrada en la promoción democrática.

La alternancia en el gobierno federal en el año 2000, después de setenta años de un mismo partido en el poder, conducen a debatir la necesidad de adecuar las estrategias y los principios de la política exterior mexicana a la nueva realidad nacional. El nuevo gobierno basado en su "bono democrático" decide emprender una política exterior activa, de defensa de la democracia y los derechos humanos, la cual se relaciona íntimamente con las transformaciones sufridas en el México de fin de siglo, en clara tendencia hacia la democracia.

En los años noventa, el ámbito internacional, ya había surtido efecto, modificando tres condicionantes básicos de la política exterior: "El modelo de desarrollo, el tipo de régimen y el contexto externo" (ob. Cit, p. 156). Además, busca desmarcarse del antiguo régimen, poniendo un especial énfasis en la aceptación de la observación internacional sobre prácticas democráticas, particularmente electorales y de derechos humanos. Si bien el gobierno de Vicente Fox no es el primero en abrirse al escrutinio internacional. Éste sí "busca rectificar la posición internacional del país dada la transición a la democracia, para lo cual era indispensable mostrar una nueva actitud hacia el exterior" (Sotomayor, A. 2010, p. 228).

Aquí se revisarán las cuatro variables que han incidido históricamente en la capacidad del gobierno para profundizar la democracia: 1) Relaciones con otros países, 2) la competitividad del ámbito económico internacional, 3) los límites impuestos por agentes externos y 4) la influencia de las ONG. Aquí nos centraremos en cuatro actores centrales que han influido en el cambio democrático en México: 1) Estados Unidos, 2) la ONU, 3) la OEA-ALCA y 4) La Unión Europea. 
López De Lara, D. (2014). Cuatro factores internacionales para el cambio democrático en México (1990-2006). Collectivus, Revista de Ciencias Sociales, 1, (1), 46-69. Julio - Diciembre. ISSN: 2382-4018

\section{Estados Unidos y el comercio}

"Históricamente, la prioridad del gobierno estadounidense en México ha sido la estabilidad más que la democracia" (Covarrubias, A. 2001, p. 330). Los gobiernos de Estados Unidos se abstienen de criticar a México por no practicar plenamente la democracia, mientras éste garantizara la estabilidad política y social. Sin embargo, la clase gobernante comienza a prestar atención y demostrar inquietud por la situación interna de México, a partir de la crisis de la deuda y por el tema del narcotráfico ${ }^{3}$. Aunque el principal factor de influencia de Estados Unidos sobre México es el comercial.

El tema económico constituye, en efecto, una medida en la que los gobiernos de México se van acercando a las posiciones estadounidenses; con las privatizaciones, la reducción de la participación del Estado en la economía o la apertura a la inversión extranjera. La cúspide de esta afinidad es la firma del TLCAN (1994), donde los gobiernos de George Bush (padre) y Bill Clinton evitan señalar las deficiencias expresas de prácticas democráticas y de violaciones a los derechos humanos. Para ellos, la firma del Tratado constituye una prueba de que México iba en la buena dirección para mejorar su situación interna. El libre mercado contribuiría a mejorar las condiciones de vida de las personas, así como contribuir a la democracia mexicana.

Como lo señala extensa bibliografía: El libre comercio fortalece la democracia. López-Córdova, E. y Meissner, L.M. (2004), en un estudio cuantitativo, utilizando modelos econométricos, indican que los países que fueron expuestos al comercio internacional son menos propensos a convertirse en autoritarios. Es decir, entre más intercambio comercial, se tiende a ser más democrático. O los trabajos de Milner, H.V. y Kubota, K. (2005, p. 107) quienes postulan que el cambio de régimen hacia la democracia está normalmente asociado a la liberalización comercial. Esta relación ha sido ampliamente

\footnotetext{
${ }^{3}$ El narcotráfico constituye una fuente inagotable de tensión bilateral desde 1985. Esta fecha corresponde al asesinato de un agente de la DEA, Enrique Camarena por autoridades mexicano
} 
López De Lara, D. (2014). Cuatro factores internacionales para el cambio democrático en México (1990-2006). Collectivus, Revista de Ciencias Sociales, 1, (1), 46-69. Julio - Diciembre. ISSN: 2382-4018

estudiada, y existe el consenso en lo general, que el libre comercio necesita de un esquema democrático y viceversa. Así los acuerdos comerciales dependen del régimen del país:

[y] Estados que son más democráticos, son cada vez más propensos a consumar acuerdos comerciales... y aquellos que violan sus compromisos internacionales -disparan la alarma- ante otros participantes o a la organización encargada de monitorear el acuerdo, pudiendo generar costosas consecuencias a nivel doméstico y evidentemente en el ámbito internacional (Mansfield, E. Milner, H.V. \& Rosendorff, B.P. 2002, p. 480).

Es así que el factor externo marca definitivamente la opción de México por el libre comercio, la integración regional y por consiguiente la democracia.

Para el presidente Carlos Salinas (1988-1994), ambas reformas no podían tener lugar, ya que había que mantener el control de los cambios económicos, necesarios para el ajuste después de la firma del TLCAN. En otras palabras, el esquema autoritario del sistema político mexicano, le permite a Salinas llevar a cabo las reformas económicas, sin que existiera por ejemplo, como desde 1997, un Congreso dividido, o una oposición política más firme. Aunque como lo muestra el estudio de Wayland (2002, pp. 21-22) "el apoyo público para emprender reformas al mercado, incluidas la liberalización del comercio, fue en realidad muy fuerte en la mayor parte de los países latinoamericanos". No obstante Fishlow (1990) "muestra que estas reformas no fueron visiblemente opuestas". Para el caso de México, algunos miembros de la sociedad civil y pocas organizaciones muestran su oposición al Tratado, en lo general, los empresarios respaldan a Salinas; la oposición más perceptible se da en amplios sectores de Estados Unidos.

A finales de los años ochenta se comienza a cuestionar la capacidad de los gobiernos del PRI para mantener la estabilidad en el país. Por ejemplo, el senador republicano, Jesse Helms realiza una serie de audiencias en Estados Unidos en las que dibuja un México al borde de la revolución, resultado de la corrupción rampante, el intervencionismo estatal en la economía y el fraude 
López De Lara, D. (2014). Cuatro factores internacionales para el cambio democrático en México (1990-2006). Collectivus, Revista de Ciencias Sociales, 1, (1), 46-69. Julio - Diciembre. ISSN: 2382-4018

electoral (Gutiérrez González, 1987, citado por Covarrubias, A. 2001, pp. 333334). Esto hace que Estados Unidos comience a mirar al Partido Acción Nacional (PAN), más ideológicamente afín a ellos. Para las elecciones de 1988, cuando el Frente Democrático Nacional (FDN-de izquierda) aparece como una alternativa electoral real, "Estados Unidos deja de apoyar la -transición mexicana-" (ob. Cit., 2001, pp. 333-334).

Aunque, el discurso oficial de Estados Unidos, de Bush (padre) y Clinton era favorable a las políticas gubernamentales orientadas al cambio político en México. Las relaciones bilaterales se centraron en la negociación del TLCAN y evitaron emitir juicios sobre la falta de democracia en México. No obstante, Bush expresa su satisfacción por las medidas adoptadas por el gobierno mexicano, como el establecimiento de la Comisión Nacional de Derechos Humanos (CNDH-1990), la elaboración de un nuevo código electoral (COFIPE1993) y el triunfo del PAN en Baja California en 1989. Según Covarrubias, los funcionarios estadounidenses no emitieron juicios, posiblemente pensaban que Salinas iba en la buena dirección y que la condena abierta podría traer un debilitamiento en su desempeño.

Clinton por su parte, enfrenta a una situación más inestable que su predecesor, ya que las elecciones de 1994 y los eventos que acompañan a todo el proceso político de ese año, como los asesinatos políticos de Luis Donaldo Colosio (candidato del PRI a la presidencia) o José Francisco Ruiz Massieu (secretario general del PRI), o el levantamiento zapatista, generan una grave inestabilidad política y foco de atención de la comunidad internacional. El presidente Clinton, por razones económicas y comerciales, no emite juicios negativos, mostrando un voto de confianza a su homólogo mexicano, Ernesto Zedillo. Él cual comienza a mostrar una cierta apertura a la crítica y la observación externa sobre los asuntos internos.

Después de toda una serie de recomendaciones y presiones, México accede a aceptar observadores internacionales en las elecciones de 1994. Sin embargo, como señala Covarrubias, esto sucede una vez que las tendencias electorales favorecían al PRI; los actores internacionales confirmarían y legitimarían así los resultados y el triunfo del PRI. Tan es así, que el gobierno 
López De Lara, D. (2014). Cuatro factores internacionales para el cambio democrático en México (1990-2006). Collectivus, Revista de Ciencias Sociales, 1, (1), 46-69. Julio - Diciembre. ISSN: 2382-4018

de Estados Unidos califica dichas elecciones como "limpias y legítimas"; a pesar de que algunos observadores independientes, como la Fundación Carter, el Instituto Republicano Internacional, señalan que habían existido irregularidades, aunque ello no había alterado el resultado.

Finalmente, para las elecciones del año 2000, los observadores internacionales, particularmente la Fundación Carter reconocen que "las irregularidades y la violencia en las urnas habían quedado en el pasado y que éstas se habían dado en un clima de armonía, paz y buena voluntad" (Ob. Cit., 2001, pp. 333-334). Las reacciones mostraron una gran civilidad democrática, con la que el presidente saliente y los distintos actores internos aceptan los resultados, mandando señales favorables al medio internacional. Zedillo felicita a Fox y éste reconoce la aportación democrática de Zedillo, los partidos de oposición reconocen el triunfo del PAN.

Los medios de comunicación como Le Monde, dan una amplia cobertura a la elección y reconocen a Zedillo como el gran artífice de la transición democrática, fundada con esta alternancia o cambio en el gobierno (Abellard, A. Le Monde, 2000). Esta transición "pone fin a la dictadura perfecta que durante 70 años mantiene el PRI". ${ }^{4}$ Para Jorge Castañeda, "esta elección es un referéndum entre el cambio y la continuidad en el poder del PRI." (Abellard, A.) Por otra parte, la transparencia y la aceptación del resultado tranquiliza a los inversionistas, constatado con un importante indicador, que es la alza del 6\% del peso frente al dólar.

El aspecto electoral constituye una asignatura pendiente de la democracia en México, también lo es, el tema de los derechos humanos. El levantamiento zapatista es bien manejado por las autoridades mexicanas, ya que se privilegia el diálogo al uso de la fuerza. El estudio de Covarrubias muestra la influencia benigna de Estados Unidos en el proceso democrático mexicano; aunque su imperio estuvo centrado en la aceptación del libre comercio.

\footnotetext{
${ }^{4}$ Este término es con el que el escritor peruano, Mario Vargas Llosa define al sistema político mexicano. André Renaud, "Les Mexicains mettent fin à 71 ans d'hégémonie du PRI. ANALYSELa fin d'une «dictature parfaite ». Le Monde, 4 de julio 2000
} 
López De Lara, D. (2014). Cuatro factores internacionales para el cambio democrático en México (1990-2006). Collectivus, Revista de Ciencias Sociales, 1, (1), 46-69. Julio - Diciembre. ISSN: 2382-4018

\section{ONU: Procesos electorales y derechos humanos}

Tanto la ONU como la OEA han participado en procesos electorales y en la defensa de los derechos humanos en México, a solicitud del gobierno mexicano o sin su consentimiento. Como lo señala Covarrubias (2001), "la presencia de la ONU en México refleja la ruta de apertura del gobierno". En 1994, la ONU asiste las elecciones, lo cual representa el punto de partida para que el gobierno de Zedillo "abriera más la puerta" a los distintos representantes de la organización. "La invitación a la ONU es indicativa del paso de una interpretación estricta de la no intervención en los asuntos mexicanos a una posición más accesible".

A pesar de lo que sostienen algunos funcionarios mexicanos de que es con el gobierno de Fox que se inicia este "nuevo" discurso de defensa de los derechos humanos y la democracia para aceptar la observación internacional. Lo cierto es que a finales del sexenio de Salinas, se invita a la ONU para que brinde "asesoría técnica" al proceso electoral mexicano. Zedillo intensifica esta labor, haciendo de la firma del Acuerdo Global con la Unión Europea su más importante dossier en política exterior. Los acuerdos de la UE con terceros países incluyen la "cláusula democrática", la cual obliga a los países "socios" a respetar la democracia y los derechos humanos en sus respectivos territorios. Fox, en efecto no es el primero en "abrir la puerta", pero sí hace del tema una prioridad muy visible de su gobierno, si no es que la más importante en materia de política exterior.

Al aproximarse las elecciones presidenciales de 1994, la élite intelectual y política mexicana temía que las elecciones carecieran de legitimidad, como las celebradas en 1988. En la búsqueda de legitimidad, se invita a la oficina de asistencia electoral de la ONU a México, para venir a capacitar a los observadores electorales y elaborar un informe sobre las elecciones. Su presencia, y la existencia del nuevo Instituto Federal Electoral (IFE) compuesto por ciudadanos independientes, hacen posible que las elecciones de ese año 
López De Lara, D. (2014). Cuatro factores internacionales para el cambio democrático en México (1990-2006). Collectivus, Revista de Ciencias Sociales, 1, (1), 46-69. Julio - Diciembre. ISSN: 2382-4018

fueran calificadas como un avance en la democracia mexicana (Pellicer, O. 2006, pp. 356-357). Finalmente se lleva a cabo una reforma electoral, que lleva a la completa "ciudadanización" del IFE y la creación de diversos mecanismos para asegurar la transparencia de los procesos electorales en México. Es así que para el año 2000, el tema de las elecciones en México ya no tenía motivos para ser defensivo, al contrario, estaba listo para ser un país modelo en el tema ${ }^{5}$.

\subsection{Derechos humanos}

Además de la observación electoral, durante el sexenio de Zedillo, otros representantes de la ONU visitan México, con el fin de "evaluar" la situación de los derechos humanos: El relator de la Comisión contra la tortura, Nigel Rodley; el secretario general de la ONU, Kofi Annan; la relatora especial para ejecuciones extrajudiciales, sumarias o arbitrarias, Asma Jahangir; y la alta comisionada de Naciones Unidas de los Derechos Humanos (ACNUDH), Mary Robinson (1997-2002). Estas visitas no estuvieron exentas de acusaciones y fuertes diagnósticos que mostraron graves violaciones a los derechos humanos por parte de autoridades mexicanas.

Sin embargo, se registra una actitud más receptiva de las autoridades mexicanas (Covarrubias, 2001). El secretario de Relaciones Exteriores, José Ángel Gurría (1994-1998), durante la visita de Rodley dijo que el gobierno aceptaría las recomendaciones de la Comisión contra la tortura, "con el ánimo de mejorar la capacidad de identificar y castigar a quienes incurran en ese delito. Esto forma parte de la nueva actitud ante temas de derechos humanos que se relaciona con la democracia en el país".

En 1999, y penúltimo año de gobierno de Zedillo, visitan el país, la relatora especial, Asma Jahangir y la alta comisionada, Mary Robinson. La relatora puso especial atención en los casos de Acteal, El Bosque, Aguas

\footnotetext{
${ }^{5}$ En estas elecciones, la ONU realiza un proceso de observación, apoyando a grupos nacionales en vez de traerlos del exterior. La ONU hace una evaluación global del sistema electoral mexicano, el resultado es el cuestionamiento de ciertos procedimientos, pero no la victoria del PRI.
} 
López De Lara, D. (2014). Cuatro factores internacionales para el cambio democrático en México (1990-2006). Collectivus, Revista de Ciencias Sociales, 1, (1), 46-69. Julio - Diciembre. ISSN: 2382-4018

Blancas y El Charco (todas ellas ejecuciones extrajudiciales, sumarias y/o arbitrarias), así como en los asesinatos de las mujeres en Ciudad Juárez. Ante estos casos consideró que "las disposiciones del gobierno para asegurar el derecho a la vida, la proporcionalidad y pertinencia del uso de la fuerza por las fuerzas armadas, la confiabilidad de las investigaciones, las acciones para juzgar a los responsables sin importar su posición pública u oficial, el gobierno presentaba deficiencias para tomar las medidas para evitar estas tragedias, las cuales en muchos casos, contaron con la complicidad del gobierno."

Además se reconoce, que "México cuenta con los recursos necesarios para proteger la vida de los ciudadanos", recomendando reformas al sistema judicial, electorales y se fortalezca a las localidades, buscando la solidez económica con la sinceridad y determinación política (ob. Cit.). Sin embargo, Jahangir señaló que pudo realizar su trabajo sin ningún obstáculo, en libertad y acceso a los individuos y a las ONG.

El informe de Jahangir provocó la reacción de la SRE y del procurador de la República, Jorge Madrazo, quienes lo calificaron de "carente de equilibrio y objetividad". La SRE expresó: "La relatora rebasó su mandato al entrar en el terreno de los procesos electorales y en el papel que desempeñan las fuerzas armadas." Madrazo se muestra sorprendido de la imagen que se hace la relatora sobre la impunidad en México, y dijo "creo que ella en su país o en el ámbito internacional, no se atrevería a hacer una acusación sobre casos de impunidad, sin ofrecer pruebas."

Con la alta comisionada de la ONU en derechos humanos (ACNUDH), Mary Robinson se firma un Memorando de Intención para el Desarrollo y Aplicación de Programas de Cooperación Técnica en el Campo de los Derechos Humanos, mediante el cual el gobierno mexicano puede aprovechar los servicios de asesoría y cooperación técnica que ofrece la ONU (ob. Cit). El 2 de diciembre de 2000, un día después de entrar en funciones, el presidente Fox firma el Acuerdo de Cooperación Técnica con la ACNUDH. Esto después de que la visita de Robinson y Jahangir durante el gobierno de Zedillo constató, "el mal estado de los derechos humanos en México", recomendando reformas legislativas para superar las deficiencias en procuración de justicia. También 
López De Lara, D. (2014). Cuatro factores internacionales para el cambio democrático en México (1990-2006). Collectivus, Revista de Ciencias Sociales, 1, (1), 46-69. Julio - Diciembre. ISSN: 2382-4018

coincidieron sobre la impunidad que prevalece en Chiapas, la existencia de grupos armados, la violación en las comunidades indígenas y el sufrimiento de los migrantes. Aunque, se reconocieron esfuerzos del gobierno mexicano y que "la visita fue muy constructiva, describí el abismo entre lo que se dice y lo que se hace en realidad en el terreno".

\section{Sistema Interamericano (OEA) y cláusula democrática}

La firma de la Carta de Bogotá en 1948 da como resultado la creación de la OEA, ahí México se compromete a adoptar como forma de gobierno la "democracia representativa", y que la falta de ella constituiría una razón para dejar de pertenecer al organismo multilateral. Según Covarrubias (2001), este organismo ha hecho poco para garantizar esta forma de gobierno, aunque al fin de la guerra fría, el sistema interamericano pone en marcha nuevas medidas para promover la democracia en la región.

Durante los años ochenta se hacen cada vez más visibles las irregularidades en los procesos electorales en México. El PRI, como partido hegemónico, utiliza una serie de artimañas políticas para hacerse de votos y en varios casos defraudar las elecciones, particularmente las locales. EI PAN recurre a organismos internacionales, especialmente a la Comisión Interamericana de Derechos Humanos $(\mathrm{CIDH})$ de la OEA. Ante la cual interpone una serie de quejas: Como para la elección de diputados en Chihuahua (1985); las elecciones municipales en Durango (1986); o para la gubernatura de Chihuahua ese mismo año; así como las municipales en el Estado de México en 1990. El gobierno mexicano descalifica a la CIDH, negando su jurisdicción en México, a pesar de haber firmado la Convención Americana de Derechos Humanos o Pacto de San José en 1969. El gobierno de México $^{6}$, argumenta que el PAN no había agotado todos los recursos internamente y que la CIDH no es un instrumento válido para juzgar procesos electorales en México. Sin embargo, la CIDH procede a analizar las quejas del

\footnotetext{
${ }^{6}$ No se debe olvidar que aquí el gobierno y el partido político, el PRI se encuentran fusionados, es decir, la posición de uno es también la posición del otro
} 
López De Lara, D. (2014). Cuatro factores internacionales para el cambio democrático en México (1990-2006). Collectivus, Revista de Ciencias Sociales, 1, (1), 46-69. Julio - Diciembre. ISSN: 2382-4018

PAN y recomienda al gobierno cumplir las recomendaciones, para garantizar el libre y pleno ejercicio de los derechos políticos.

Independientemente del ámbito electoral, al cual los gobiernos de Salinas y Zedillo consideran atentatorios al principio de no intervención y muestran reticencias para aceptar las recomendaciones de los organismos internacionales. En los noventa esta resistencia disminuye y en 1996 el gobierno permite la visita de la CIDH y reconoce su competencia en 1998. Esto muestra la respuesta del gobierno a presiones externas.

La OEA es de las pocas organizaciones internacionales que tiene como fin, inscrito en su propia carta constitutiva, la defensa de la democracia representativa, aunque dentro del marco del respeto de la no intervención. La contraposición de ambos postulados es materia de debates y tensiones, entre expertos y gobiernos (Ruiz-Cabañas, M. pp. 2002, 227). A fin del siglo XX se inicia una "renovación" del sistema interamericano, refrendando los compromisos de los estados miembros con la democracia. El Secretario General de la OEA, César Gaviria (1994-2004), define las actividades de dicha organización:

Todo el andamiaje de nuestra diplomacia preventiva, del uso de procedimientos pacíficos para el manejo de crisis y de la acción posconflicto está fundado en el principio de la defensa de la democracia. Fortalecer las democracias es un elemento importantísimo para asegurar la paz entre y dentro de los Estados. Es nuestro paradigma de solidaridad. (Milet, P.V., p. 2005).

Es así que a lo largo de esta década, la OEA aprueba diversas resoluciones y declaraciones estableciendo mecanismos de reacción inmediata frente a golpes de Estado, más bien de carácter reactivo que "preventivo". Un ejemplo de esto es la experiencia peruana del caso Fujimori (presidente del Perú 1990-2000, destituido por el Congreso), sirve para catalizar un ambiente más favorable a la adopción de medidas colectivas, mediante la "cláusula democrática" (suspensión a la participación en todos los órganos de la OEA) al país que produjera un golpe de Estado o un autogolpe (Ob. Cit). 
López De Lara, D. (2014). Cuatro factores internacionales para el cambio democrático en México (1990-2006). Collectivus, Revista de Ciencias Sociales, 1, (1), 46-69. Julio - Diciembre. ISSN: 2382-4018

Para Grossman, este caso muestra los límites de la resolución 1080; "por una falta de voluntad política regional y por minusvalorar la reacción democrática que el autoritarismo de Fujimori generaba en su país. La OEA no actuó decisivamente, sino hasta el final, a pesar de la represión de los opositores políticos democráticos, la corrupción generalizada, los ataques contra la libertad de expresión y el ejercicio de un control prácticamente absoluto pobre el poder judicial del Perú”. Esta situación ocurre a pesar de los más de 100 casos presentados contra Perú en el sistema interamericano de derechos humanos y de los informes de la CIDH que señalaban el deterioro del país.

\subsection{Cláusula democrática (2001)}

El tema de la democracia se hace patente en la III Cumbre de las Américas, celebrada en Quebec, Canadá en 2001. En donde se plantea un "Plan de Acción para fortalecer la democracia representativa, promover la eficiente gestión de gobierno y proteger los derechos humanos y libertades fundamentales". "El mantenimiento y fortalecimiento del Estado de Derecho y el respeto estricto al sistema democrático son un propósito y compromiso compartido en ésta y en futuras Cumbres. En consecuencia, cualquier alteración o ruptura inconstitucional del orden democrático en un estado del hemisferio constituye un obstáculo insuperable para la participación del Gobierno de dicho Estado en el proceso de Cumbres de las Américas". Se insta a los ministros de Relaciones Exteriores que, en el marco de la próxima Asamblea General de la OEA, preparen una Carta Democrática Interamericana que refuerce los instrumentos de dicha organización para la defensa activa de la democracia representativa ${ }^{7}$.

\footnotetext{
${ }^{7}$ Venezuela expresa reservas de la Declaración de Quebec, en cuanto a que la democracia debe ser entendida en su sentido más amplio y no únicamente en su carácter representativo. "Entendemos que el ejercicio democrático abarca además la participación de los ciudadanos en la toma de decisiones y en la gestión de gobierno, con miras a la construcción diaria de un proceso dirigido al desarrollo integral de la sociedad." El gobierno de Venezuela hubiese preferido que en el texto de la Declaración quedase reflejado el carácter participativo de la democracia. "Declaración de Quebec", http://www.summit-americas.org/iii summit.html consultado mayo 2011
} 
López De Lara, D. (2014). Cuatro factores internacionales para el cambio democrático en México (1990-2006). Collectivus, Revista de Ciencias Sociales, 1, (1), 46-69. Julio - Diciembre. ISSN: 2382-4018

En el mismo documento de la Declaración de Quebec, se establece la fecha para la puesta en marcha de un Área de Libre Comercio de las Américas (ALCA). Donde se solicita a los ministros de los países integrantes a concluir el acuerdo a más tardar en enero 2005, para que su entrada en vigencia no sea más allá de diciembre de ese mismo año:

Esto constituye un elemento clave para generar el crecimiento económico y la prosperidad en el Hemisferio, y contribuirá al logro de los amplios objetivos de la Cumbre. El Acuerdo deberá ser equilibrado, comprensivo, y congruente con las reglas y disciplinas de la Organización Mundial del Comercio (OMC), y deberá constituir un compromiso único. Otorgamos gran importancia a que el diseño del acuerdo tenga en cuenta las diferencias en tamaño y niveles de desarrollo de las economías participantes.

Si bien la Carta Democrática es firmada por todos los Estados miembros, conforme avanzan las negociaciones, algunos países comienzan a mostrar sus diferencias con las condiciones del ALCA, argumentando que las asimetrías de las economías no están siendo tomadas en cuenta, sobre todo ante la negativa de que Estados Unidos disminuya los subsidios agrícolas.

Los conflictos en las negociaciones del ALCA no vinieron por la cláusula democrática, sino por la divergencia de intereses y por no tomar en cuenta las asimetrías de las economías. En la Cumbre de las Américas celebrada en Mar del Plata, Argentina en 2005 se declaran "muertas" las negociaciones y paralelamente se ven fortalecidos otros esfuerzos integracionistas sudamericanos. Tales como el MERCOSUR-después UNASUR, el ALBA como una alianza entre los países llamados de izquierda latinoamericanos tales como Cuba, Venezuela, Bolivia y Ecuador.

\section{Unión Europea y la cláusula democrática.}

Como lo señala Covarrubias, la firma del Acuerdo de Asociación Comercial y Cooperación Política (AACCP), conocido como el Acuerdo Global, firmado entre México y la Unión Europea constituye un caso de condicionalidad 
López De Lara, D. (2014). Cuatro factores internacionales para el cambio democrático en México (1990-2006). Collectivus, Revista de Ciencias Sociales, 1, (1), 46-69. Julio - Diciembre. ISSN: 2382-4018

democrática. En el pasado los gobiernos mexicanos habían evitado concluir los acuerdos con la Comunidad Económica Europea (CEE). En 1991 se firma el Acuerdo, que no incluye la cláusula democrática y de derechos humanos; sin embargo, para el gobierno de Ernesto Zedillo, éste acuerdo constituye la iniciativa más valiosa en su agenda de política exterior (Arrieta, citado por Covarrubias, 2001, p. 362). Finalmente se acepta la incorporación de la cláusula democrática, antes calificada de intervencionista, instalando una nueva relación con la vieja doctrina.

El gobierno de Salinas había cambiado su interés de firmar un acuerdo comercial con los europeos a causa de esta premisa, los estadounidenses, como se mencionó, sólo se preocupaban por la estabilidad y las inversiones. Con Zedillo se muestran algunas reticencias ante esta cláusula, como las declaraciones de José Ángel Gurría, secretario de Relaciones Exteriores: "Nadie podrá enseñar a México cómo ser democráticos"; aunque después se desdijo: "por supuesto que siempre estuvimos a favor de la cláusula democrática" (Rosas, citada por Prado Lallande, J.P. 2008, p. 412).

México se encontraba en transición, se habían emprendido esfuerzos en la discusión abierta sobre los derechos humanos con los organismos internacionales. En marzo de 2000, se firma la Declaración de Lisboa, entre Zedillo, el primer ministro de Portugal, Antonio Guterres y el presidente en turno de la Comisión Europea, Romano Prodi. El cambio de posición del gobierno mexicano resalta con la hábil declaración al respecto del subsecretario de Asuntos Multilaterales, Marco Provencio, quien declara sobre la cláusula: "Realmente no ha sido un problema, nunca hubo una diferencia sustantiva entre la UE y México, porque ambos coincidimos en la importancia de los principios democráticos y el respeto a los derechos humanos". Además ambas partes coincidieron en que guiarían sus políticas externas e internas inspiradas en los derechos humanos y en los principios de cada soberanía (Covarrubias, 2001, p. 362).

El AACCP se firma en diciembre de 1997 y entra en vigor en octubre de 2000, este Acuerdo contiene tres capítulos principales: El económicocomercial, política y cooperación. La parte comercial, no es objeto de este 
López De Lara, D. (2014). Cuatro factores internacionales para el cambio democrático en México (1990-2006). Collectivus, Revista de Ciencias Sociales, 1, (1), 46-69. Julio - Diciembre. ISSN: 2382-4018

apartado, pero lo novedoso y enriquecedor de esta nueva relación bilateral incluye la cooperación política, mediante la institucionalización del diálogo político sobre temas bilaterales e internacionales de interés común.

Pero es a Fox a quien le corresponde inaugurar el acuerdo con Europa. En su primera gira, como presidente electo (octubre 2000) visita países como Francia, España, Alemania, Bélgica y el Reino Unido, quienes lo reciben con "alfombra roja" y mucho interés por lo que significa el cambio democrático en México $^{8}$. La ambiciosa agenda en materia de política exterior constituye un atractivo al comprometerse a respetar los derechos humanos, resolver el conflicto en Chiapas y abrir los sectores de telecomunicaciones y energético a la inversión extranjera ${ }^{9}$. Además de que a México se le considera un interlocutor privilegiado entre Europa y América Latina.

Las giras del año 2001 sirven para mostrar este nuevo énfasis en los derechos humanos dentro del ámbito multilateral. El presidente Fox busca ubicar a México como un socio clave en la relación birregional entre América Latina y el Caribe y la Unión Europea, logrando acoger la III Cumbre Birregional (2004) (a esta reunión asisten los diez nuevos miembros de la UE). Las buenas relaciones y prestigio con el que cuenta México en América Latina y dentro del Grupo de Río, le permiten presentarse como el articulador de diversas posiciones de la región con Europa.

Este énfasis en los derechos humanos le vale a Fox una invitación al Consejo de Europa ${ }^{10}$ como observador en mayo 2002. Sin embargo, los europeos comienzan a mostrar su desencanto ante el desempeño del gobierno mexicano en este rubro. En ese mismo año, el Consejo presenta un Informe Estratégico Nacional donde se definen las prioridades y presupuestos de la

\footnotetext{
8 "Mexico's Fox Gets the European Red Carpet", Financial Times, 29 de septiembre 2000. Citado por Lorena Ruano, 2010, p. 316

9 "Le meilleur pays pour investir en Amérique Latine", Le Monde, 3 de octubre 2000. Citado por Ruano, ob. Cit, p. 316.

${ }^{10} \mathrm{La}$ autora sugiere aclarar que no es lo mismo el Consejo Europeo y al Consejo de Ministros de la UE con el Consejo de Europa, organismo internacional no vinculado formalmente a la UE que vela por la protección de los derechos humanos y la promoción de la democracia en el continente europeo.
} 
López De Lara, D. (2014). Cuatro factores internacionales para el cambio democrático en México (1990-2006). Collectivus, Revista de Ciencias Sociales, 1, (1), 46-69. Julio - Diciembre. ISSN: 2382-4018

Unión Europea para con sus socios. Dentro del documento se destaca que la situación de los derechos humanos continua siendo "ambivalente e incierta".

Aunque el documento reconoce los esfuerzos de los niveles más altos del Estado, es decir, la altísima prioridad acordada por la nueva administración, aunque los temas pendientes siguen siendo el sistema judicial, las policías, el clima de violencia, la impunidad generalizada y la expansión del mandato del ejército (ob. Cit, pp. 317-318). Es así que la Comisión Europea destina un alto presupuesto para coadyuvar a consolidar el Estado de derecho y acciones específicas en derechos humanos como un área prioritaria para la cooperación política con México.

En 2003, el contexto mundial de la guerra de Irak divide a la UE, y México todavía no lograba traducir en hechos el respeto de los derechos humanos y la administración de justicia en el país. Diversas ONGs mexicanas y trasnacionales hacen llegar al Parlamento Europeo una serie de denuncias, pidiéndole "dientes" a la cláusula democrática del Acuerdo Global (ob. Cit, pp. 318-319). Entretanto, el Senado mexicano seguía sin ratificar el Estatuto de Roma (lo ratifica con reservas en octubre 2005). Esto muestra las dificultades que encuentra Fox para concretar internamente esta parte de la agenda, la cual los europeos valoran enormemente.

\section{Conclusión}

Las nuevas condiciones económicas externas reorientan la política exterior de México hacia un pragmatismo en sus relaciones internacionales. Sin embargo, temas pendientes como la alternancia política y la protección de derechos humanos, así como la transparencia en los procesos electorales van sufriendo adecuaciones que iban imponiéndose del exterior. Para el gobierno de Salinas la situación se iba haciendo cada vez más difícil, ante el fraude electoral y el control total de los factores políticos para poder llevar a cabo el más grande proyecto de México en los procesos de integración regional.

Para Zedillo, las condiciones de cuasi ingobernabilidad política frente a los acontecimientos de 1994 y la crisis financiera influyen de manera 
López De Lara, D. (2014). Cuatro factores internacionales para el cambio democrático en México (1990-2006). Collectivus, Revista de Ciencias Sociales, 1, (1), 46-69. Julio - Diciembre. ISSN: 2382-4018

determinante para que el gobierno mexicano mostrara una actitud de apertura frente a los organismos internacionales. Los ámbitos electoral y de derechos humanos fueron piezas claves del cambio democrático en México. Las elecciones del año 2000 marcan definitivamente la elección por la democracia, aunque si bien se registran grandes retrocesos, lo cierto es que este momentum es bien aprovechado por el gobierno de Fox, quien emprende acciones de vinculación internacional con la protección de los derechos humanos que no pueden echarse atrás.

Aún así las condiciones democráticas en México todavía distan mucho de ser ejemplares, es importante destacar los esfuerzos que se han emprendido en la materia, los cuales cuentan con la influencia del ámbito internacional. Muy probablemente sin la presión externa, México hubiera tardado mucho más en llevar a cabo esta apertura. La dimensión internacional de los procesos políticos internos muestra la íntima relación entre la política interna o doméstica con el sistema internacional, prueba fehaciente de los efectos positivos de la globalización.

\section{Referencias Bibliográficas}

Abellard, A. (2000, 5 de Julio). Analyse-Ernesto Zedillo. Le président qui a organisé la transition. Le Monde.

Acosta, M. (2003). Hacia una política en favor de los derechos humanos como valores universales. Revista Mexicana de Política Exterior, (67-68).

Ballesteros, C. (2004). América Latina y Europa: modernidad e integración. Revista Mexicana de Política Exterior, SRE, (71).

Castañeda Gutman, J. (2000). Apuntes de política exterior para el gobierno de Vicente Fox: 2000-2006. En C. Elizondo \& L. Maira (Eds.). Chile-México. Dos transiciones frente a frente. México: CIDE/Grijalbo/Prochile. 
López De Lara, D. (2014). Cuatro factores internacionales para el cambio democrático en México (1990-2006). Collectivus, Revista de Ciencias Sociales, 1, (1), 46-69. Julio - Diciembre. ISSN: 2382-4018

Castañeda Gutman, J. (2001). El nuevo activismo internacional mexicano. Revista mexicana de Política Exterior, (64).

Castañeda Gutman, J. (2002). Palabras del canciller Jorge G. Castañeda en la Comisión de Derechos Humanos de la ONU. Revista Mexicana de Política Exterior, (66).

Castañeda Gutman, J. (2002). El factor externo y consolidación de la democracia en México. Reforma.

Covarrubias, A. (2001). El ámbito internacional y el proceso de cambio político en México. En R.Y. Ortega Ortiz. Caminos a la democracia, Colegio de México.

De Beer, P. (2000, 5 de Julio). Les États-Unis se félicitent de l'élection du nouveau Président mexicain Vicente Fox. Le Monde.

Gómez Camacho, J.J. (2001). La protección de los derechos humanos: Codificación, mecanismos y vinculación con México. Revista Mexicana de Política Exterior, (62-63).

González González, G. (2006). Las bases internas de la política exterior: realidades y retos de la apertura económica y la democracia. En L. HerreraLasso (Coord.), México ante el mundo: tiempo de definiciones. México: FCE.

Gourevitch, P. (1978). The Second Image Reversed: The International Sources of Domestic Politics. International Organization, 32 (4).

Grossman, C. (2001). El fortalecimiento de la democracia: El sistema interamericano de derechos humanos. Foreign Affairs, otoño-invierno.

Guajardo Soto, G. (2010). Viejos puentes y nuevos acervos: La relación de México con América Latina y el Caribe durante el sexenio de Vicente Fox. En H. Garza Elizondo (Ed.), J. Schiavon \& R. Velázquez (Coord.), Paradigmas y paradojas de la política exterior de México: 2000-2006. México: Colegio de México/CIDE. 
López De Lara, D. (2014). Cuatro factores internacionales para el cambio democrático en México (1990-2006). Collectivus, Revista de Ciencias Sociales, 1, (1), 46-69. Julio - Diciembre. ISSN: 2382-4018

Human Rights Watch (2006). El Cambio Inconcluso. Avances y Desaciertos en Derechos Humanos durante el Gobierno de Fox, 16 de mayo. Recuperado 17 de septiembre de 2010, [No disponible] http://www.hrw.org/en/reports/2006/05/16/mexico-lost-transition-0consultado mayo2011.

Keohane, R.O., Macedo, S. \& Moravcsik, A. (2009). Democracy-Enhacing Multilateralism. International Organization, (63).

Le Monde (2000 5 de julio). Les capitales étrangères et les marchés financiers Applaudissent.

López-Córdoba, E. \& Meissner, C.M. (2004). Globalization and Democracy, 1870 2000. Recuperado el 8 de marzo [En línea].

Mansfield, E., Milner, H.V. \& Rosendorff, B.P. (2002). Why Democracies Cooperate More: Electoral Control and International Trade Agreements. International Organization, 56 (3).

Mansfield, E. \& Pevehouse, J.C. (2006). Democratization and International Organizations". International Organization, 68(1).

Milet, P.V. (2005). El rol de la OEA. El difícil camino de prevención y resolución de conflictos a nivel regional. Revista Futuros, 3 (10). Recuperado 3 de diciembre de 2013, [en línea], http://www.revistafuturos.info

Milner, H.V. \& Kubota, K. (2005). Why the Move to Free Trade? Democracy and Trade Policy in the Developing Countries. International Organization, (59).

Pellicer, O. (2006). México y la nueva agenda internacional. En Jorge Eduardo Navarrete (coord.). La reconstrucción de la política exterior de México: principios, ámbitos, acciones. México: Centro de Investigaciones Interdisciplinarias en Ciencias y Humanidades/UNAM.

Pellicer, O. \& González Iza, D. (2008). La política de México hacia los derechos humanos en el ámbito internacional. En J. E. Navarrete (coord.), Miscelánea 
López De Lara, D. (2014). Cuatro factores internacionales para el cambio democrático en México (1990-2006). Collectivus, Revista de Ciencias Sociales, 1, (1), 46-69. Julio - Diciembre. ISSN: 2382-4018

global. Tareas internacionales de México. México: Centro de Investigaciones Interdisciplinarias en Ciencias y Humanidades/UNAM.

Prado Lallande, J.P. (2008). Política exterior mexicana, democracia y derechos Humanos. En Consuelo Dávila Pérez et al., La política exterior de México y sus nuevos desafíos. México: UNAM/Plaza y Valdés.

Putnam, R.D. (1998). Diplomacy and Domestic Politics: the logic of two-level Games. International Organization, 42 (3).

Renaud, A. (2000, 4 de julio). Les Mexicains mettent fin à 71 ans d'hégémonie du PRI.ANALYSE - La fin d'une «dictature parfaite. Le Monde.

Roche, J.J. (2005). Relations Internationales, Manuel, L.G.D.J., Paris.

Ruano, L. (2010). De la exaltación al tedio: Las relaciones entre México y la Unión Europea durante el sexenio del presidente Vicente Fox, 2000-2006. En H. Garza Elizondo (Ed.), J. Schiavon \& R. Velázquez. Paradigmas y paradojas de la política exterior de México: 2000-2006. México: Colegio de México/CIDE. Ruiz-Cabañas, M. (2002). México en el hemisferio. En R. Fernández de Castro (Coord.), México en el mundo 2002. Cambio y continuidad en la política exterior de México. México: Ariel/ITAM.

Salas, F. (2002). Democracia y derechos humanos como política exterior. En R. Fernández de Castro (coord.). México en el mundo 2002. Cambio y continuidad en la política exterior de México. México: Ariel/ITAM.

Secretaría de Relaciones Exteriores (2005). La política exterior mexicana en la Transición. México: FCE/Colección Editorial del Gobierno del Cambio.

Sotomayor, A.C. (2010). México y la ONU en tiempos de transición: Entre activismo externo, parálisis interna y crisis internacional. En H. Garza Elizondo (Ed.), J.Schiavon \& R. Velázquez (Coord.), Paradigmas y paradojas de la política exterior de México: 2000-2006. México: Colegio de México/CIDE. 